\title{
Diagnóstico situacional das farmácias vivas no estado do Ceará
}

\author{
Situational diagnosis of existing healthy living pharmacies \\ in the state of Ceará
}

Diagnóstico situacional de las farmacias vivas existentes en el estado del Ceará

\author{
Danuta Yelena Goiana BONFIM ${ }^{(1)}$ \\ Aleksandra Barroso GOMES (2) \\ Angélica Regina Lima BRASIL (2) \\ Karla do Nascimento MAGALHÃES (2) \\ Kellen Miranda SÁ ${ }^{(2)}$ \\ Mary Anne Medeiros BANDEIRA ${ }^{(2)}$
}

Recebido: 23 maio 2017 Revisado: 17 nov 2017 Aceito: 21 nov 2017

\section{Autor de}

correspondência: Danuta Yelena Goiana Bonfim

danutabonfim@gmail.com

Conflito de interesses: Os autores declaram não haver nenhum interesse profissional ou pessoal que possa gerar conflito de interesses em relação a este manuscrito.

\footnotetext{
(1) Universidade Federal do Ceará - UFC, Faculdade de Farmácia, Odontologia e Enfermagem FFOE, Departamento de Enfermagem, Fortaleza, CE, Brasil.

(2) Universidade Federal do Ceará - UFC, Faculdade de Farmácia, Odontologia e Enfermagem FFOE, Departamento de Farmácia, Fortaleza, CE, Brasil.
}

\section{Resumo}

O Programa Farmácias Vivas - FV foi criado em 1983 pelo professor Francisco José de Abreu Matos para garantir à população plantas medicinais e fitoterápicos com garantia de qualidade. Objetivou-se realizar um diagnóstico situacional das FV existentes no Ceará após o Decreto $n^{\circ} 30.016 / 2009$. Pesquisa básica, descritiva, documental com abordagem quantitativa. Estudo realizado com dados dos 184 municípios cearenses. Os 116 documentos fornecidos pelo Horto Oficial e Horto Matriz foram coletados entre agosto/2015 a agosto/2016, gerados em banco de dados estruturado no programa Microsoft Excel-2016, analisados em números relativos, absolutos e análise descritiva. Foram encontrados registros de: 58 (56,3\%) FV de natureza governamental, 28 (48,3\%) classificadas como modelo I e 26 (44,8\%) em inatividade; 26 (25,2\%) FV não governamentais, 13 (50\%) classificadas como modelo I e 9 (34,6\%) em funcionamento; 15 $(14,6 \%) \mathrm{FV}$ instaladas em instituições de ensino superior, dessas, 10 (66,6\%) classificadas no modelo I e $09(60,1 \%)$ em atividade. Ao todo, foram encontrados registros de 99 (100\%) FV, estando 42 (42,4\%) em atividade. A maioria das FV está inserida no modelo I, de menor complexidade, o que pode estar relacionado à falta de recursos financeiros. As FV de natureza governamental apresentaram o maior número de unidades inativas o que pode ter sido provocado pela incapacidade dos órgãos públicos em se adequar às exigências do Decreto $n^{\circ} 30.016 / 2009$. Percebe-se que o principal desafio que se impõe às FV é a falta de financiamento específico e permanente que garanta a expansão do programa e manutenção das unidades implantadas.

Descritores: Atenção Primária à Saúde; Fitoterapia; Plantas Medicinais; Políticas Públicas de Saúde; Saúde Pública. 


\begin{abstract}
The Program Healthy Live Pharmacies (HLP) was created in 1983 by Professor Francisco José de Abreu Matos to ensure the population medicinal plants and herbal medicines with quality assurance. The objective of this study was to carry out a situational diagnosis of HLP in the state of Ceará after Decree 30.016 / 2009. Basic, descriptive, documentary research with a quantitative approach. The study was carried out with data referring to the 184 municipalities of Ceara. Data from the study were collected between August 2015 and August 2016. We analyzed 116 documents provided by the Official Horto and Matriz Horto. The data were generated in a database structured in the program Microsoft Excel2016, analyzed in relative, absolute numbers and descriptive analysis. There were records of: There were records of: 58 (56.3\%) HLP of governmental nature, 28 (48.3\%) classified as model I, 43 (74.1\%) held by the Municipal Secretariats of their respective municipalities and 26 (44.8\%) in inactivity; 26 (25.2\%) non-governmental HLP, 13 (50\%) classified in model I and 9 (34.6\%) were found in full operation; 15 (14.6\%) HLPs installed in higher education institutions, were found, of which 10 (66.6\%) were classified in model I and 09 (60.1\%) in full activity. In all, records of 99 (100\%) FV were found, of which 42 (42.4\%) were active. It is noted that most of the HLP, both governmental and nongovernmental, is inserted in model I, of less complexity, which may be related to the lack of financial resources. The HLP of a governmental nature had the largest number of inactive units, which may have been caused by the inability of public agencies to comply with the requirements of Decree 30.016 / 2009. In view of this, it is perceived that the main challenge imposed on the HLP is the lack of specific and permanent financing that guarantees the expansion of the program and maintenance of the implemented units.
\end{abstract}

Keywords: Primary Health Care; Phytotherapy; Medicinal Plants; Public Health Policy; Public Health.

\title{
Resumen
}

El Programa Farmacias Vivas - FV fue creado en 1983 por el profesor Francisco José de Abreu Matos para asegurar a la población plantas medicinales y hierbas medicinales con garantía de calidad. El objetivo de este estudio fue realizar un diagnóstico de la situación de FV en el estado de Ceará después del Decreto 30.016/2009. Una investigación documental básica, descriptiva con un enfoque cuantitativo. El estudio se realizó con datos de los 184 municipios de Ceará. Los datos del estudio fueran compilados entre agosto de 2015 y agosto de 2016. Analizamos 116 documentos ofertados por el Horto Oficial y Horto Matriz. Los datos se generaron en una base de datos estructurada en el programa Microsoft Excel-2016, analizada en números relativos, absolutos y con análisis descriptiva. Se registraron: 58 (56.3\%) FV de carácter gubernamental, 28 (48.3\%) clasificadas como modelo I, y 26 (44.8\%) en inactividad; 26 (25.2\%) FV no gubernamentales, 13 (50\%) clasificadas en el modelo I y 9 (34.6\%) se encontraron en plena operación; Se encontraron 15 (14.6\%) FV instaladas en instituciones de educación superior, de las cuales 10 (66.6\%) se clasificaron en el modelo I y 09 (60.1\%) en plena actividad. En total, se encontraron registros de 99 (100\%) FV, de las cuales 42 (42.4\%) están activas. Se observa que la mayor parte de las FV, tanto gubernamentales como no gubernamentales, se inserta en el modelo I, de menor complejidad, lo que puede estar relacionado a la falta de recursos financieros. Las FV de carácter gubernamental tenían el mayor número de unidades inactivas, lo que puede haber sido causado por la incapacidad de los organismos públicos para cumplir con los requisitos del Decreto 30.016 / 2009. En vista de esto, se percibe que el principal desafío impuesto a las FV es la falta de financiamiento específico y permanente que garanta la expansión del programa y el mantenimiento de las unidades implementadas.

Palabras-claves: Atención primaria de salud; Fitoterapia; Plantas medicinales; Política de salud pública. 


\section{Introdução}

O professor da Universidade Federal do Ceará - UFC Francisco José de Abreu Matos criou, no ano de 1983, o Programa Farmácias Vivas. ${ }^{1}$ Para a criação desse programa, foram catalogadas várias plantas medicinais de uso popular que, depois de estudadas, passaram a compor o rol de plantas do Programa Farmácias Vivas. Esse programa está vinculado à UFC, a qual integra a Política Pública de Plantas Medicinal e Fitoterápica no Ceará, tornando-se referência para experiências em outros estados brasileiros. ${ }^{2}$

As Farmácias Vivas - FV podem ser definidas como unidades farmacêuticas implantadas em comunidades públicas ou privadas, formadas por fitoterápicos preparados a partir de plantas medicinais com eficácia comprovada, colhidas nas próprias hortas, na maioria dos casos instaladas no mesmo local. ${ }^{3}$

As principais atividades desenvolvidas pelo Programa Farmácias Vivas são: a pesquisa bibliográfica e experimental de plantas medicinais do Nordeste brasileiro, a seleção de plantas por meio de critérios farmacognósticos, a aplicação de técnicas agronômicas de coleta, adaptação e cultivo das plantas selecionadas, a preparação e distribuição de mudas para a implantação de novas FV e a prestação de assessoria técnico-científica para as comunidades que utilizam a fitoterapia como opção terapêutica. ${ }^{4}$

O trabalho realizado nas Farmácias Vivas é capaz de garantir à população dois tipos de atendimento na área de fitoterapia: o primeiro é a preparação de fitoterápicos segundo técnicas farmacêuticas, com prescrição e dispensação na rede pública de saúde e o segundo, a orientação sobre o uso correto de plantas medicinais com apoio técnico-científico de um farmacêutico, a partir de hortos constituídos por espécies vegetais com certificação botânica, sendo assegurado, dessa forma, garantia de eficácia, segurança e qualidade ${ }^{1}$

A Secretaria de Saúde do Estado - SESA com o apoio do professor Francisco José de Abreu Matos, no ano de 1997, deu início a institucionalização das FV com a criação do Centro Estadual de Fitoterapia. ${ }^{3}$ No ano de 1999, foi promulgada a Lei Estadual $n^{\circ} 12.951$, 
que dispõe sobre a implantação da Fitoterapia em Saúde Pública no Estado do Ceará, por meio da implantação de unidades de Farmácias Vivas. ${ }^{5}$

No ano de 2007, foi firmado um convênio entre a UFC e a SESA para a implantação e implementação de unidades de $\mathrm{FV}^{3}$ Nesse mesmo ano, o Centro Estadual de Fitoterapia foi transformado em Núcleo de Fitoterápicos - NUFITO que integra o Programa Farmácias Vivas e compõe a Coordenadoria de Assistência Farmacêutica - COASF da SESA. O NUFITO tem como objetivo disseminar o projeto FV com a implantação e implementação de unidades em organizações governamentais e não-governamentais, associações e comunidades organizadas. $^{6}$

Para a regulamentação da Lei Estadual n 12.951, somente dez anos depois e tendo influência das Política Nacional de Práticas Integrativas e Complementares - PNPIC e Política Nacional de Plantas Medicinais e Fitoterápicos - PNPMF, em 2009, foi publicado o Decreto $n^{\circ} 30.016$ que trata sobre o Regulamento Técnico que se aplica a todas as etapas da produção de fitoterápicos pela Farmácia Viva. ${ }^{6}$

O referido decreto, estabeleceu critérios específicos a serem atendidos pelas Farmácias Vivas, bem como uma classificação em virtude do seu grau de complexidade: sendo o modelo I o menos complexo com produção de plantas medicinais in natura, o modelo II o intermediário com produção e dispensação de plantas medicinais secas e o modelo III o mais complexo, com preparação de fitoterápicos para dispensação em unidades de saúde do Sistema Único de Saúde - SUS. ${ }^{6}$

Em âmbito nacional, as FV foram instituídas no SUS somente no ano de 2010, por meio da Portaria MS/GM n 886 de 20 de abril, o que demonstra o pioneirismo do estado do Ceará na regulamentação da fitoterapia. Essa portaria determinou que a gestão da Farmácia Viva fosse de responsabilidade do estado, município ou Distrito Federal; que a Farmácia Viva executasse desde o cultivo à dispensação de preparações fitoterápicas; proibiu a comercialização de plantas medicinais e fitoterápicos e tornou a FV sujeita a regulamentação sanitária e ambiental específicas dos órgãos regulamentadores. ${ }^{7}$ 
Em 2011, considerando a necessidade de adequar o Sistema de Cadastro Nacional de Estabelecimentos de Saúde - SCNES às novas Políticas instituídas, o Ministério da Saúde, inclui na Tabela de Serviços/Classificação do SCNES, com o código 125, o serviço de Farmácia e com a classificação 007, a Farmácia Viva. ${ }^{8}$

Em âmbito estadual, após a publicação do Decreto regulamentador $n^{\circ} 16.030$ de 30 de dezembro de 2009, o NUFITO iniciou o cadastramento das FV, de natureza governamental, existentes nos municípios do estado do Ceará conforme preconizava a normativa. Esse cadastramento foi iniciado em 2010, ano subsequente ao decreto, e continua até os dias atuais.

Em 2016, a PNPI instituída pela Portaria n 971, de 03 de maio de $2006{ }^{9}$ e a Política Nacional de Plantas Medicinais e Fitoterápicos - PNPMF regulamentada pelo Decreto $\mathrm{n}^{\circ}$ 5.813 de $2006^{10}$ completaram 10 anos de publicação. As diretrizes da PNPMF foram, em seguida, detalhadas no Programa Nacional de Plantas Medicinais e Fitoterápicos, Portaria Interministerial $n^{\circ} 2.960$ de $2008 .^{11}$

Com o presente estudo, objetivou-se realizar um diagnóstico situacional das FV existentes no estado do Ceará, após o Decreto nº 30.016 de 2009, que regulamentou a Lei $\mathrm{n}^{\circ} 12.951$ de 1999, os quais foram reflexos da PNPIC.

\section{Metodologia}

Os dados foram coletados no Horto de Plantas Medicinais Francisco José de Abreu Matos da Universidade Federal do Ceará (Horto Matriz) e no NUFITO/COASF/SESA (Horto Oficial). O estudo foi realizado com os dados referentes aos 184 municípios do estado do Ceará. Trata-se de uma pesquisa básica, descritiva, documental a partir de dados secundários com abordagem quantitativa.

Foram fornecidos 119 documentos no total, três documentos foram descartados por não apresentarem relação direta com as FV no estado do Ceará. Os outros 116 documentos 
foram selecionados por conterem informações sobre: o local onde a Farmácia Viva estava inserida, ano de sua instalação, natureza, situação atual, modelo, plantas medicinais distribuídas, fitoterápicos produzidos ou dados sobre a instituição na qual a FV estava instalada.

Os dados extraídos dos documentos analisados foram gerados em banco de dados estruturado no programa Microsoft Excel-2016 e analisados em números relativos e absolutos bem como uma análise descritiva.

Os dados foram coletados entre os meses de agosto de 2015 a agosto de 2016. Os itens analisados nos documentos foram: nome da Farmácia Viva; macro, microrregião de saúde e município onde está instalada; ano de instalação; natureza (governamental, não governamental); vínculo (universidades, faculdades); situação atual (ativa ou inativa); modelo (I, II ou III); fitoterápicos preparados e dados sobre a instituição. Foi solicitada a autorização institucional ao Horto Oficial e ao Horto Matriz para realização da pesquisa através do Termo de Autorização de Fiel Depositário e da Carta de Anuência.

\section{Resultados e discussão}

O Programa de Plantas Medicinais e Aromáticas do Nordeste, que em 28 anos de trabalho extraiu mais de 3000 óleos essenciais e analisou quase 1.000 espécies vegetais nordestinas, $^{3}$ foi o prelúdio para as FV. ${ }^{2}$

O Programa FV têm como objetivo proporcionar, sem fins lucrativos, assistência farmacêutica à população através do estímulo ao uso correto de plantas medicinais, próprias da região e com atividades terapêuticas cientificamente comprovadas, a partir dos conhecimentos populares, e como missão, realizar a disseminação do programa, com capacitação de profissionais, assessoria técnica-científica, sempre respeitando os princípios da ética, sustentabilidade e desenvolvimento social onde estão inseridas. ${ }^{1}$

As FV podem ser definidas como unidades farmacêuticas implantadas em comunidades públicas ou privadas, formadas por plantas medicinais com eficácia 
comprovada, colhidas nas próprias hortas, na maioria dos casos instaladas no mesmo local. ${ }^{3}$

O primeiro passo para a constituição de FV consiste na escolha adequada das plantas medicinais. Essa triagem deve ser baseada em estudo epidemiológico regional e validação científica das plantas por meio de um processo participativo. ${ }^{1}$

O Quadro 1 demonstra que 43 (74,1\%) FV são mantidas pelas Secretarias Municipais de Saúde de seus respectivos municípios, 16 (27,6\%) possuíam vínculo com o Centro Vocacional Tecnológico - CVT e 09 (15,5\%) com a Secretaria da Ciência, Tecnologia e Educação Superior do Estado do Ceará - SECITECE.

\begin{tabular}{|c|c|c|c|c|}
\hline Município & Nome & Modelo & $\begin{array}{c}\text { Ano de } \\
\text { Implantação }\end{array}$ & Situação Atual \\
\hline Acaraú & $\begin{array}{l}\mathrm{SMS}^{+} \\
\text {Integrada ao } \\
\mathrm{CVT}^{\ddagger}\end{array}$ & I & $\mathrm{S} / \mathrm{I}^{\S}$ & $\begin{array}{l}\text { Inativa. Em fase de reativação. Ainda possui } \\
\text { canteiros, mas não trabalham com plantas } \\
\text { medicinais porque não existem instrutores. }\end{array}$ \\
\hline Aratuba & $\mathrm{SMS}^{+}$ & III & $\mathrm{S} / \mathrm{I}^{\varsigma}$ & $\begin{array}{c}\text { Inativa. Possuía Horto de Plantas Medicinais, } \\
\text { mas a Oficina Farmacêutica funcionava no } \\
\text { Hospital. Não possuía condições técnicas de } \\
\text { continuar com as características de Modelo III, } \\
\text { segundo Decreto no } 30.016 / 2009 . \\
\text { Desativada devido à falta de condições } \\
\text { técnicas e de manutenção. }\end{array}$ \\
\hline Amontada & $\begin{array}{l}\text { SECITECE } \\
\qquad \mathrm{CVT}^{\ddagger}\end{array}$ & I & $\mathrm{S} / \mathrm{I}^{\S}$ & $\begin{array}{l}\text { Ativa. Possuem Horto de Plantas Medicinais } \\
\text { com cultivo em canteiros e espaço para } \\
\text { ampliação. }\end{array}$ \\
\hline Barbalha & $\begin{array}{l}\mathrm{SMS}^{\dagger} \\
\text { Integrada ao } \\
\mathrm{CVT}^{\ddagger}\end{array}$ & III & 2000 & $\begin{array}{c}\text { Inativa/ Em vias de reativação. Ainda possuem } \\
\text { Horto de Plantas Medicinais e estrutura da } \\
\text { Oficina Farmacêutica. }\end{array}$ \\
\hline Barreira & $\begin{array}{l}\text { SECITECE } \\
\qquad \mathrm{CVT}^{\ddagger}\end{array}$ & I & $\mathrm{S} / \mathrm{I}^{\S}$ & $\begin{array}{l}\text { Ativa. Possui Horto de Plantas Medicinais com } \\
\text { cultivo em canteiros. }\end{array}$ \\
\hline Beberibe & $\begin{array}{l}\mathrm{SMS}^{+} \\
\text {Integrada ao } \\
\mathrm{CVT}^{\ddagger}\end{array}$ & I & $\mathrm{S} / \mathrm{I}^{\S}$ & $\begin{array}{l}\text { Ativa. Possui canteiros e Oficina Farmacêutica } \\
\text { com potencial para Modelo III }\end{array}$ \\
\hline Boa Viagem & $\begin{array}{l}\mathrm{SMS}^{+} \\
\text {Integrada ao } \\
\mathrm{CVT}^{\ddagger}\end{array}$ & I & $\mathrm{S} / \mathrm{I}^{\S}$ & $\begin{array}{l}\text { Inativa. Desativada devido à falta de } \\
\text { condições técnicas e de manutenção. Possui } \\
\text { poucos canteiros e estão desativados. Não há } \\
\text { água suficiente para irrigar as plantas } \\
\text { medicinais. O abastecimento de água era feito } \\
\text { por meio de caminhões pipa. }\end{array}$ \\
\hline 7 & & & & J Manag Prim Health Care, 2018;9:e15 \\
\hline
\end{tabular}




\begin{tabular}{|c|c|c|c|c|}
\hline Camocim & $\mathrm{SMS}^{+}$ & III & $S / I^{\S}$ & $\begin{array}{l}\text { Inativa. Não possuía condições técnicas para } \\
\text { continuar com as características de Modelo III, } \\
\text { segundo Decreto n } 30.016 / 2009 . \\
\text { Desativada devido à falta de condições } \\
\text { técnicas e de manutenção. }\end{array}$ \\
\hline Cascavel & $\mathrm{SMS}^{+}$ & III & $S / 1^{\S}$ & $\begin{array}{c}\text { Inativa. Desativada devido à falta de } \\
\text { manutenção. }\end{array}$ \\
\hline Caucaia & $\begin{array}{l}\text { Parque } \\
\text { Botânico do } \\
\text { Ceará } \\
\text { (Secretaria } \\
\text { do Meio } \\
\text { Ambiente) }\end{array}$ & II & $S / 1^{\S}$ & $\begin{array}{l}\text { Ativa. É uma Unidade de Conservação em } \\
\text { processo de revisão para adequação ao } \\
\text { Sistema Nacional de Unidades de } \\
\text { Conservação da Natureza. }\end{array}$ \\
\hline Crateús & $\begin{array}{l}\mathrm{SMS}^{+} \\
\text {Integrada ao } \\
\mathrm{CVT}^{\ddagger}\end{array}$ & III & 2000 & $\begin{array}{l}\text { Inativa. Desativada devido à falta de } \\
\text { condições técnicas e de manutenção. Ainda } \\
\text { possui canteiros, mas falta água. }\end{array}$ \\
\hline Eusébio & $\begin{array}{c}\mathrm{SMS}^{+} \text {e CAPS } \\
\text { ADI }\end{array}$ & I & $S / I^{\S}$ & $\begin{array}{l}\text { Ativa. Implantada em 2016, com maior ênfase } \\
\text { na produção de Erva Cidreira (Lippia alba), } \\
\text { quimiotipo II, planta medicinal calmante e } \\
\text { ansiolítica. }\end{array}$ \\
\hline Forquilha & $\mathrm{SMS}^{+}$ & III & $S / 1^{\S}$ & $\begin{array}{l}\text { Inativa. Não possuía condições técnicas de } \\
\text { continuar com as características de Modelo III, } \\
\text { segundo Decreto n } 30.016 / 2009 . \\
\text { Desativada devido à falta de condições } \\
\text { técnicas e de manutenção. }\end{array}$ \\
\hline Fortaleza & $\begin{array}{c}\text { Centro } \\
\text { Estadual de } \\
\text { Fitoterapia } \\
\text { em } 2007 \\
\text { tornou-se } \\
\text { NUFITO*/ } \\
\text { COASF }^{* *} / \\
\text { SESA }^{++}\end{array}$ & $\begin{array}{l}\text { Horto } \\
\text { Oficial III }\end{array}$ & 2007 & $\begin{array}{l}\text { Ativa. O Horto Oficial (Decreto } n^{\circ} 30.016 / \\
\text { 2009) produz mudas certificadas e dá apoio } \\
\text { técnico-científico para implantação e } \\
\text { implementação de unidades de FV. Possui } \\
\text { oficina Farmacêutica para preparação de } \\
\text { fitoterápicos. }\end{array}$ \\
\hline Fortaleza & $\begin{array}{l}\text { Secretaria do } \\
\text { Trabalho e } \\
\text { Desenvolvi- } \\
\text { mento Social } \\
\text { (Espaço Viva } \\
\text { Gente) }\end{array}$ & II & $S / I^{\S}$ & $\begin{array}{l}\text { Ativa. Visa atender crianças e adolescentes em } \\
\text { situação de risco e/ou vulnerabilidade social } \\
\text { com atividades socioeducativas prestando um } \\
\text { trabalho com plantas medicinais integrado } \\
\text { com a família e a comunidade. }\end{array}$ \\
\hline Fortaleza & $\begin{array}{l}\mathrm{SMS}^{+}(\text {Horto } \\
\text { Municipal } \\
\text { Falconete } \\
\text { Fialho) }\end{array}$ & I & 1991 & $\begin{array}{l}\text { Ativa. Produz matéria prima para a oficina } \\
\text { farmacêutica Maria Lúcia Gurgel, necessitando } \\
\text { de reestruturação. Mantido pela Empresa } \\
\text { Municipal de Limpeza Urbana (Emlurb), } \\
\text { produz principalmente mudas ornamentais, } \\
\text { florestais e frutíferas usadas no paisagismo. }\end{array}$ \\
\hline
\end{tabular}




\begin{tabular}{|c|c|c|c|c|}
\hline Fortaleza & $\begin{array}{l}\text { SMS }^{+} \\
\text {(Farmácia } \\
\text { Viva Maria } \\
\text { Lúcia } \\
\text { Fernandes } \\
\text { Gurgel) }\end{array}$ & III & 1994 & $\begin{array}{l}\text { Ativa. Passou por um período de inatividade. } \\
\text { Reativada quando da integração da Oficina } \\
\text { Farmacêutica com a UNIFOR }{ }^{++1+} \text {. As plantas } \\
\text { medicinais são cultivadas no Horto Municipal } \\
\text { Falconete Fialho no Passaré. }\end{array}$ \\
\hline Fortaleza & $\begin{array}{l}\text { SMS }^{\dagger} \text { (Centro } \\
\text { de Saúde } \\
\text { Manuel } \\
\text { Carlos de } \\
\text { Gouveia) }\end{array}$ & III & 1992 & $\begin{array}{c}\text { Inativa. A preparação de fitoterápicos foi } \\
\text { direcionada para uma única oficina } \\
\text { farmacêutica (Lúcia Gurgel) para a garantia da } \\
\text { qualidade. }\end{array}$ \\
\hline Fortaleza & $\begin{array}{l}\text { SMS }^{+} \text {(Centro } \\
\text { de Saúde } \\
\text { Filgueiras } \\
\text { Lima - } \\
\text { Parangaba) }\end{array}$ & III & 1993 & $\begin{array}{c}\text { Inativa. A preparação de fitoterápicos foi } \\
\text { direcionada para uma única oficina } \\
\text { farmacêutica (Lúcia Gurgel) para a garantia da } \\
\text { qualidade. }\end{array}$ \\
\hline Fortaleza & $\begin{array}{l}\text { Secretaria do } \\
\text { Desenvolvi- } \\
\text { mento } \\
\text { Agrário } \\
\left(\text { Embrapa }^{\S \S}\right)\end{array}$ & III & $S / 1^{\S}$ & $\begin{array}{l}\text { Inativa. Desativada em } 1997 \text { para dar lugar ao } \\
\text { Programa Estadual de Fitoterapia, atual } \\
\text { Núcleo de Fitoterápicos da Coordenadoria de } \\
\text { Assistência Farmacêutica da Secretaria da } \\
\text { Saúde do Estado do Ceará. }\end{array}$ \\
\hline Fortaleza & $\begin{array}{l}\text { SMS+ (CAPS } \\
\text { AD } \text { Al Alto da } \\
\text { Coruja - } \\
\text { Itaperi) }\end{array}$ & I & 2006 & $\begin{array}{l}\text { Ativa. Importante trabalho de terapia } \\
\text { ocupacional no Horto de Plantas Medicinais } \\
\text { com orientação sobre preparações caseiras } \\
\text { para os pacientes atendidos e familiares. }\end{array}$ \\
\hline Fortaleza & $\begin{array}{l}\text { Embrapa }^{\S \S}- \\
\text { Campus do } \\
\quad \text { Pici }\end{array}$ & $N / C^{\#}$ & 1997 & $\begin{array}{l}\text { Ativa. Pesquisa em Melhoramento e Recursos } \\
\text { Genéticos com Plantas Medicinais. } \\
\text { Implantado com apoio do Horto Matriz da } \\
\text { UFClll.. }\end{array}$ \\
\hline Horizonte & $\mathrm{SMS}^{+}$ & III & $S / I^{\S}$ & $\begin{array}{l}\text { Ativa. A Oficina Farmacêutica e a produção de } \\
\text { fitoterápicos é mantida pela Secretaria da } \\
\text { Saúde, sendo o Horto de Plantas Medicinais } \\
\text { de propriedade de empresa privada para } \\
\text { produção e fornecimento de plantas } \\
\text { medicinais e matéria-prima (Fazenda Ipu - } \\
\text { Estrada do Dourado). }\end{array}$ \\
\hline Icapuí & $\mathrm{SMS}^{+}$ & III & 1998 & $\begin{array}{l}\text { Inativa. Não possuía condições técnicas de } \\
\text { continuar com as características de Modelo III, } \\
\text { segundo Decreto } n^{\circ} 30.016 / 2009 \text {. } \\
\text { Desativada devido à falta de condições } \\
\text { técnicas e de manutenção. }\end{array}$ \\
\hline Iguatu & $\mathrm{SMS}^{+}$ & III & 1994 & $\begin{array}{l}\text { Inativa. Não possuía condições técnicas de } \\
\text { continuar com as características de Modelo III, } \\
\text { segundo Decreto } n^{\circ} 30.016 / 2009 \text {. }\end{array}$ \\
\hline
\end{tabular}




\begin{tabular}{|c|c|c|c|c|}
\hline Ipaumirim & $\begin{array}{l}\text { SECITECE" e } \\
\qquad \mathrm{CVT}^{\ddagger}\end{array}$ & I & $\mathrm{S} / \mathrm{I}^{\S}$ & $\begin{array}{l}\text { Inativa. Existe Horto de Plantas Medicinais. Os } \\
\text { canteiros possuem } 13 \text { espécies medicinais } \\
\text { com potencial para reativação. }\end{array}$ \\
\hline Ipu & $\begin{array}{l}\text { SECITECEE e } \\
\qquad \mathrm{CVT}^{\ddagger}\end{array}$ & I & $\mathrm{S} / \mathrm{I}^{\S}$ & $\begin{array}{l}\text { Inativa. Desativada devido à falta de } \\
\text { condições técnicas e de manutenção. Existem } \\
\text { ainda canteiros com } 13 \text { espécies medicinais } \\
\text { com potencial para ativação. }\end{array}$ \\
\hline Iracema & $\mathrm{SMS}^{+}$ & III & 1994 & $\begin{array}{l}\text { Inativa. Não possuía condições técnicas de } \\
\text { continuar com as características de Modelo III, } \\
\text { segundo Decreto nº } 30.016 / 2009 \text {. } \\
\text { Desativada devido à falta de condições } \\
\text { técnicas e de manutenção. }\end{array}$ \\
\hline Itaitinga & $\mathrm{SMS}^{+}$ & I & 2000 & $\begin{array}{l}\text { Ativa. Foi classificada em anos anteriores } \\
\text { como Modelo III. Atualmente realiza somente } \\
\text { as atividades relacionadas ao Modelo I. }\end{array}$ \\
\hline Itapajé & $\begin{array}{l}\text { Secretaria do } \\
\text { Meio } \\
\text { Ambiente }\end{array}$ & I & 1993 & $\begin{array}{l}\text { Inativa/ Em vias de reativação. Ainda possui } \\
\text { canteiros. }\end{array}$ \\
\hline Itapipoca & $\mathrm{SMS}^{+}$ & I & 1998 & $\begin{array}{l}\text { Ativa. Foi classificada em anos anteriores } \\
\text { como Modelo III. Atualmente realiza somente } \\
\text { as atividades relacionadas ao Modelo I, } \\
\text { destacando-se atividades educativas junto às } \\
\text { escolas públicas de ensino fundamental. }\end{array}$ \\
\hline Jucás & $\mathrm{SMS}^{+}$ & I & 1994 & $\begin{array}{l}\text { Inativa. Desativada devido à falta de } \\
\text { condições técnicas e de manutenção. }\end{array}$ \\
\hline Maracanaú & $\mathrm{SMS}^{+}$ & III & 1983 & $\begin{array}{l}\text { Ativa. Desde } 2014 \text { encontra-se em fase de } \\
\text { reestruturação da Oficina Farmacêutica para } \\
\text { adequação ao Decreto n 30.016/ } 2009 \text {. }\end{array}$ \\
\hline Maranguape & $\begin{array}{l}\text { Secretaria } \\
\text { Municipal do } \\
\text { Meio } \\
\text { Ambiente } \\
\text { em } \\
\text { integração } \\
\text { com a SMS }\end{array}$ & I & 1997 & $\begin{array}{c}\text { Ativa. Reestruturada em 2016. Foi classificada } \\
\text { em anos anteriores como Modelo III, quando } \\
\text { integrada ao CVT. Atualmente funciona na } \\
\text { "IIEITA. Nesta estação foi implantado um } \\
\text { Horto de Plantas Medicinais com potencial } \\
\text { para Modelo III. Produz também plantas } \\
\text { ornamentais. }\end{array}$ \\
\hline Mauriti & $\begin{array}{l}\text { SECITECEE e } \\
\mathrm{CVT}^{\ddagger}\end{array}$ & I & $\mathrm{S} / \mathrm{I}^{\S}$ & $\begin{array}{l}\text { Ativa. Possuem Horto de Plantas Medicinais } \\
\text { com cultivo em canteiros. }\end{array}$ \\
\hline Morada Nova & $\mathrm{SMS}^{+}$ & I & $\mathrm{S} / \mathrm{I}^{\S}$ & $\begin{array}{l}\text { Inativa. Desativada devido à falta de } \\
\text { condições técnicas e de manutenção. }\end{array}$ \\
\hline
\end{tabular}

ISSN 2179-6750 


\begin{tabular}{|c|c|c|c|c|}
\hline Morrinhos & $\mathrm{SMS}^{+}$ & III & 2004 & $\begin{array}{l}\text { Inativa. Não possuía condições técnicas de } \\
\text { continuar com as características de Modelo III, } \\
\text { segundo Decreto nº 30.016/ } 2009 . \\
\text { Desativada devido à falta de condições } \\
\text { técnicas e de manutenção. }\end{array}$ \\
\hline Mulungu & $\mathrm{SMS}^{+}$ & I & 1993 & $\begin{array}{l}\text { Ativa. Permutou do Modelo III para I, pois não } \\
\text { possuíam condições técnicas de continuar } \\
\text { com as características de Modelo III, segundo } \\
\text { Decreto } n^{\circ} 30.016 / 2009 .\end{array}$ \\
\hline Novo Oriente & $\mathrm{SMS}^{+}$ & III & $\mathrm{S} / \mathrm{I}^{\S}$ & $\begin{array}{l}\text { Inativa. Não possuíam condições técnicas de } \\
\text { continuar com as características de Modelo III, } \\
\text { segundo Decreto n } 30.016 / 2009 . \\
\text { Desativada devido à falta de condições } \\
\text { técnicas e de manutenção. }\end{array}$ \\
\hline Pacatuba & $\begin{array}{l}\mathrm{SMS}^{\dagger} \text { em } \\
\text { integração } \\
\text { com a } \\
\text { Secretaria } \\
\text { Municipal do } \\
\text { Meio } \\
\text { Ambiente }\end{array}$ & I & $\mathrm{S} / \mathrm{I}^{\S}$ & Ativa. Em fase de estruturação. \\
\hline Pedra Branca & $\mathrm{SMS}^{+}$ & I & $S / 1^{\S}$ & $\begin{array}{l}\text { Inativa. Desativada devido à falta de } \\
\text { condições técnicas e de manutenção. }\end{array}$ \\
\hline Pereiro & $\mathrm{SMS}^{+}$ & I & $\mathrm{S} / \mathrm{I}^{\S}$ & $\begin{array}{l}\text { Ativa. Permutou de Modelo III para I, pois não } \\
\text { possuíam condições técnicas de continuar } \\
\text { com as características de Modelo III, segundo } \\
\text { Decreto } \text { n }^{\circ} 30.016 / 2009 .\end{array}$ \\
\hline $\begin{array}{l}\text { Piquet } \\
\text { Carneiro }\end{array}$ & $\begin{array}{l}\mathrm{SMS}^{\dagger} \\
\text { Integrada ao } \\
\mathrm{CVT}^{\ddagger} \text { de } \\
\text { Pentecoste }\end{array}$ & $N / C^{\ddagger}$ & $\mathrm{S} / \mathrm{I}^{\S}$ & $\begin{array}{l}\text { Inativa. Não possuía Horto de Plantas } \\
\text { Medicinais, mas realizou parceria com o CVT } \\
\text { de Pentecoste, o qual fornecia matéria-prima } \\
\text { para preparação de fitoterápicos. Utilizavam } \\
\text { material e estrutura do Hospital do Município. } \\
\text { Não possuíam condições técnicas adequadas } \\
\text { ao Decreto } n^{\circ} 30.016 / 2009 \text {. }\end{array}$ \\
\hline Quixadá & $\mathrm{SMS}^{+}$ & III & $\mathrm{S} / \mathrm{I}^{\S}$ & $\begin{array}{l}\text { Inativa. Possuía Horto de Plantas Medicinais, } \\
\text { mas a Oficina Farmacêutica funcionava no } \\
\text { subsolo do Hospital. Não possuía condições } \\
\text { técnicas de continuar com as características } \\
\text { de Modelo III, segundo Decreto } n^{\circ} 30.016 / \\
\text { 2009. Desativada devido à falta de condições } \\
\text { técnicas e de manutenção. }\end{array}$ \\
\hline Quixadá & $\begin{array}{l}\text { SECITECE } \\
\text { CVT }^{\ddagger}\end{array}$ & I & $S / 1^{\S}$ & $\begin{array}{l}\text { Ativa. Possuem Horto de Plantas Medicinais } \\
\text { com cultivo em canteiros. }\end{array}$ \\
\hline
\end{tabular}




\begin{tabular}{|c|c|c|c|c|}
\hline Quixeramobim & $\begin{array}{l}\mathrm{SMS}^{+} \\
\text {integrada ao } \\
\mathrm{CVT}^{\ddagger}\end{array}$ & III & 1998 & $\begin{array}{c}\text { Inativa. Possuía Horto de Plantas Medicinais e } \\
\text { Oficina Farmacêutica nas instalações do CVT } \\
\text { local. Desativada devido à falta de condições } \\
\text { técnicas e de manutenção. }\end{array}$ \\
\hline Quixeré & $\begin{array}{l}\text { SECITECEE e } \\
\mathrm{CVT}^{\ddagger}\end{array}$ & I & $\mathrm{S} / \mathrm{I}^{\S}$ & $\begin{array}{l}\text { Ativa. Possuem Horto de Plantas Medicinais } \\
\text { com cultivo em canteiros. }\end{array}$ \\
\hline Santa Quitéria & $\mathrm{SMS}^{+}$ & I & 1997 & $\begin{array}{l}\text { Ativa. Em fase de reestruturação. Possui } \\
\text { canteiros com ótima infraestrutura. }\end{array}$ \\
\hline São Benedito & $\begin{array}{l}\text { SECITECEE e } \\
\mathrm{CVT}^{\ddagger}\end{array}$ & I & $\mathrm{S} / \mathrm{I}^{\S}$ & $\begin{array}{l}\text { Ativa. Possui Horto de Plantas Medicinais com } \\
\text { cultivo em canteiros. }\end{array}$ \\
\hline Sobral & $\begin{array}{l}\text { SMS }^{\dagger} \text { (Centro } \\
\text { de Saúde da } \\
\text { Família - } \\
\text { Bairro } \\
\text { Sumaré) }\end{array}$ & III & $\mathrm{S} / \mathrm{I}^{\S}$ & $\begin{array}{l}\text { Ativa. Possui Horto de Plantas Medicinais para } \\
\text { o desenvolvimento de trabalhos conforme } \\
\text { modelo II. A Farmácia Escola do INTA } \\
\text { recebe a matéria-prima, prepara os } \\
\text { fitoterápicos e devolve os mesmos ao Centro } \\
\text { de Saúde. Assim, assume a característica de } \\
\text { Modelo III. }\end{array}$ \\
\hline Sobral & $\mathrm{SMS}^{+}$ & I & $\mathrm{S} / \mathrm{I}^{\S}$ & $\begin{array}{l}\text { Ativa. Possui um Horto de Plantas Medicinais } \\
\text { para apoio aos trabalhos de Terapia } \\
\text { Ocupacional e Estratégia da Saúde da Família. }\end{array}$ \\
\hline Sobral & $\mathrm{SMS}^{+}$ & I & $\mathrm{S} / \mathrm{I}^{\S}$ & $\begin{array}{l}\text { Ativa. Possui um Horto de Plantas Medicinais } \\
\text { com canteiros construídos com garrafas PET. } \\
\text { Dá apoio aos trabalhos da Estratégia da Saúde } \\
\text { da Família. }\end{array}$ \\
\hline $\begin{array}{l}\text { Tabuleiro do } \\
\text { Norte }\end{array}$ & $\begin{array}{l}\text { SECITECEE e } \\
\qquad \mathrm{CVT}^{\ddagger}\end{array}$ & I & $\mathrm{S} / \mathrm{I}^{\S}$ & $\begin{array}{l}\text { Ativa. Possuem Horto de Plantas Medicinais } \\
\text { com cultivo em canteiros. }\end{array}$ \\
\hline Tianguá & $\mathrm{SMS}^{+}$ & $\mathrm{N} / \mathrm{C}^{\#}$ & $\mathrm{~S} / \mathrm{I}^{\S}$ & $\begin{array}{l}\text { Inativa. Desativada devido à falta de condições } \\
\text { técnicas e de manutenção. }\end{array}$ \\
\hline Trairi & $\mathrm{SMS}^{+}$ & $\mathrm{N} / \mathrm{C}^{\ddagger}$ & $\mathrm{S} / \mathrm{I}^{\S}$ & $\begin{array}{l}\text { Inativa. Desativada devido à falta de condições } \\
\text { técnicas e de manutenção. }\end{array}$ \\
\hline Umirim & $\mathrm{SMS}^{+}$ & III & 2001 & $\begin{array}{l}\text { Inativa. Não possuía condições técnicas de } \\
\text { continuar com as características de Modelo III, } \\
\text { segundo Decreto } n^{\circ} 30.016 / 2009 \text {. }\end{array}$ \\
\hline Uruoca & $\mathrm{SMS}^{+}$ & III & $\mathrm{S} / \mathrm{I}^{\S}$ & $\begin{array}{l}\text { Inativa. Não possuía condições técnicas de } \\
\text { continuar com as características de Modelo III, } \\
\text { segundo Decreto } n^{\circ} 30.016 / 2009 \text {. }\end{array}$ \\
\hline $\begin{array}{l}\text { Viçosa do } \\
\text { Ceará }\end{array}$ & $\mathrm{SMS}^{+}$ & III & 2001 & $\begin{array}{l}\text { Ativa. Em fase de melhoria das instalações para } \\
\text { aumentar a preparação de fitoterápicos. }\end{array}$ \\
\hline
\end{tabular}

Quadro 1. FV de natureza governamental cadastradas pelo NUFITO, por município do estado do Ceará, com os respectivos modelos adotados e sua situação atual.

Fonte: Elaborado pelos autores (ANO). Núcleo de Fitoterápicos da Coordenadoria de Assistência Farmacêutica - "NUFITO (1983-2016). 'SMS - Secretaria Municipal de Saúde. ${ }^{\ddagger}$ CVT - Centro Vocacional Tecnológico. ${ }^{\circledR} S / I$ - 
Sem informação. "SECITECE - Secretaria da Ciência, Tecnologia e Educação Superior do Estado do Ceará. "CAPS AD - Centro de Atenção Psicossocial Álcool e Drogas. ${ }^{* *}$ COASF - Coordenadoria de Assistência Farmacêutica. ${ }^{+}$SESA - Secretaria de Saúde do Estado do Ceará. ${ }^{\ddagger}$ N/C - Não Classificada. ${ }^{\S \S}$ EMBRAPA - Empresa Brasileira de Pesquisa Agropecuária. IIIUFC- Universidade Federal do Ceará. "'EITA - Estação de Inovação de Tecnologias Ambientais. ${ }^{* * *}$ INTA - Instituto Superior de Teologia Aplicada. ${ }^{+\ldots+}$ UNIFOR - Universidade de Fortaleza.

Com relação aos modelos adotados pelas FV implantadas em organizações governamentais, 28 (48,3\%) FV estão inseridas no modelo I, duas (3,4\%) no modelo II, 24 $(41,4 \%)$ no modelo III e quatro $(6,8 \%)$ não apresentavam essa classificadas em seus registros. Não foram encontradas informações sobre o ano de implantação da maioria das FV governamentais 34 (58,6\%).

Foi possível constatar a subnotificação dos anos de implantação das FV inclusive as implantadas em instituições públicas. Isso decorre, muitas vezes, da falta de informação, por parte dos profissionais responsáveis pelo cadastro, da importância de dados fidedignos, e também, por que esses profissionais muitas vezes são responsáveis por múltiplas tarefas, relegando afazeres menos urgentes à segundo plano.

Essas 58 Farmácias Vivas foram implantadas em 47 municípios do estado do Ceará, sendo 09 (15,5\%) unidades só em Fortaleza, capital do estado. Com relação ao seu status atual, 25 (43,2\%) estão em plena atividade, 04 (6,8\%) em atividade e passando por processo de reestruturação, 26 (44,8\%) estão inativas e 03 (5,2\%) estão inativas em fase de reativação.

Das 26 Farmácias Vivas inativas, 20 (79,3\%) informou como principal motivo para a descontinuidades das ações a falta de condições técnicas e manutenção em consequência da descontinuidade política. Considerando todos os registros, $3(5,1 \%)$ unidades foram fechadas para centralizar a produção em um local com melhor infraestrutura. Em outras 2 (3,3\%) unidades o principal motivo da interrupção das atividades foi, especificamente, a falta de água para a irrigação.

Decreto $\mathrm{n}^{\circ} 30.016$ estabeleceu critérios que deveriam ser executadas pelas Farmácia Vivas a fim de garantir a qualidade de seus produtos. Desse modo, algumas 
instituições, tanto em âmbito governamental quanto não governamental enfrentaram dificuldades para se adequar às novas exigências por falta, principalmente, de financiamento. ${ }^{6}$

O Decreto n 30.016/2009 estabeleceu, inclusive, os parâmetros a serem atendidos para a adequação da estrutura física das FV desde o Horto de Plantas Medicinais até a oficina farmacêutica. O mesmo regulamento prevê a capacitação dos profissionais para as atividades desenvolvidas na Farmácia Viva, do cultivo de plantas medicinais até a dispensação do fitoterápico e orientação da comunidade. Estabeleceu, também, a responsabilidade da administração pública municipal onde a unidade para prática de fitoterapia está sediada, prever e prover: recursos humanos, infraestrutura física, equipamentos e procedimentos operacionais necessários à operacionalização das atividades das FV. Dessa forma, a partir da regulamentação da fitoterapia no estado do Ceará ficou a cargo de cada município financiar suas ações. ${ }^{6}$

Além das exigências impostas pelo Decreto regulamentador nº 30.016 de 2009, em 2013, a Anvisa publicou a resolução - RDC n 18, que dispõe sobre as boas práticas de processamento e armazenamento de plantas medicinais, preparação e dispensação de produtos magistrais e oficinais de plantas medicinais e fitoterápicos em Farmácias Vivas no âmbito do SUS, com o intuito de garantir a segurança dos produtos fornecidos pelas FV. ${ }^{12}$

Apesar do Decreto $\mathrm{n}^{\circ} 30.016$ ter previsto somente o cadastramento das Farmácias Vivas de natureza governamental, existentes no estado do Ceará, foram encontrados registros tanto no Horto Matriz quanto no Horto Oficial de FV instaladas em instituições de natureza não governamental e em instituições de ensino superior, as quais pediam apoio técnico-científico a essas instituições. O Quadro 2 apresenta as FV de natureza não governamental, por município, do estado do Ceará, com os respectivos modelos adotados e sua situação atual. 


\begin{tabular}{|c|c|c|c|c|}
\hline Município & Nome & Modelo & $\begin{array}{c}\text { Ano de } \\
\text { implantação }\end{array}$ & Situação atual \\
\hline Aquiraz & $\begin{array}{l}\text { Associação } \\
\text { Pró- } \\
\text { Desenvolvi- } \\
\text { mento da } \\
\text { Caponga }\end{array}$ & I & 1995 & $\begin{array}{l}\text { Inativa. Desativada devido à } \\
\text { falta de verbas para } \\
\text { manutenção. A Associação } \\
\text { permanece ativa, sendo sua } \\
\text { atividade principal a defesa dos } \\
\text { direitos sociais. }\end{array}$ \\
\hline Baturité & $\begin{array}{l}\text { Associação } \\
\text { de Mulheres }\end{array}$ & $\mathrm{N} / \mathrm{C}^{+}$ & $\mathrm{S} / \mathrm{I}^{\ddagger}$ & $\begin{array}{c}\text { Sem maiores informações } \\
\text { cadastrais. }\end{array}$ \\
\hline Caucaia & $\begin{array}{l}\text { Lar Fabiano } \\
\text { de Cristo }\end{array}$ & I & $\mathrm{S} / \mathrm{I}^{\ddagger}$ & $\begin{array}{l}\text { Ativa. O trabalho foi fixado, } \\
\text { após ampla semeadura nas } \\
\text { famílias das crianças. A } \\
\text { educação se configura como o } \\
\text { grande diferencial. }\end{array}$ \\
\hline Caucaia & $\begin{array}{l}\text { Farmácia } \\
\text { Viva Cura } \\
\text { Vegetal }\end{array}$ & I & $\mathrm{S} / \mathrm{I}^{\ddagger}$ & $\begin{array}{l}\text { Ativa. Está integrada ao Centro } \\
\text { Espírita Beneficente União do } \\
\text { Vegetal, o qual promove o } \\
\text { atendimento social, médico- } \\
\text { hospitalar, entre outros, aos } \\
\text { filiados e à comunidade. }\end{array}$ \\
\hline Caucaia & $\begin{array}{c}\text { Centro de } \\
\text { Apoio à } \\
\text { Criança }\end{array}$ & I & $\mathrm{S} / \mathrm{I}^{\ddagger}$ & $\begin{array}{l}\text { Sem maiores informações } \\
\text { cadastrais. }\end{array}$ \\
\hline Fortaleza & $\begin{array}{c}\text { Unidade } \\
\text { Assistencial } \\
\text { Coração de } \\
\text { Maria }\end{array}$ & I & 1995 & $\begin{array}{c}\text { Inativa. Espaço não adequado } \\
\text { para manutenção e ampliação } \\
\text { do cultivo de plantas } \\
\text { medicinais. A Unidade } \\
\text { permanece ativa, como } \\
\text { albergue para pessoas carentes. }\end{array}$ \\
\hline Fortaleza & $\begin{array}{l}\text { Projeto } 4 \\
\text { Varas }\end{array}$ & III & 1983 & $\begin{array}{l}\text { Ativa. Desenvolve uma } \\
\text { experiência de terapia na } \\
\text { comunidade do Pirambu. } \\
\text { Necessita de adequação ao } \\
\text { Decreto n 30.016/ } 2009 . \\
\text { Mantém convênio com a } \\
\text { Prefeitura Municipal de } \\
\text { Fortaleza. }\end{array}$ \\
\hline
\end{tabular}


ISSN 2179-6750

\begin{tabular}{|c|c|c|c|c|}
\hline Fortaleza & IPREDE||I & III & 1984 & $\begin{array}{l}\text { Inativa. Desativada devido a } \\
\text { contaminação do solo no local } \\
\text { onde o Horto de Plantas } \\
\text { Medicinais estava implantado. } \\
\text { Na Oficina Farmacêutica } \\
\text { preparava-se fitoterápicos com } \\
\text { fins pediátricos. O Instituto } \\
\text { permanece ativo. Passou a ser } \\
\text { denominado Instituto da } \\
\text { Primeira Infância. }\end{array}$ \\
\hline Fortaleza & $\begin{array}{l}\text { Pastoral da } \\
\text { Criança }\end{array}$ & I & $\mathrm{S} / \mathrm{I}^{\ddagger}$ & $\begin{array}{l}\text { Sem maiores informações } \\
\text { cadastrais. }\end{array}$ \\
\hline Fortaleza & $\begin{array}{c}\text { Lar Torres de } \\
\text { Melo - } \\
\text { Centro }\end{array}$ & I & $\mathrm{S} / \mathrm{I}^{+}$ & $\begin{array}{l}\text { Ativa. Possui um pequeno } \\
\text { Horto de Plantas Medicinais } \\
\text { para preparações caseiras } \\
\text { destinadas a atender as } \\
\text { necessidades dos idosos. É uma } \\
\text { instituição de longa } \\
\text { permanência para idosos, } \\
\text { especializado no atendimento } \\
\text { gerontogeriátrico. }\end{array}$ \\
\hline Fortaleza & $\begin{array}{c}F^{\prime \pi} C^{\pi}- \\
\text { Jangurussu }\end{array}$ & I & $\mathrm{S} / \mathrm{I}^{\ddagger}$ & $\begin{array}{c}\text { Ativa. Possui um pequeno } \\
\text { Horto de Plantas Medicinais } \\
\text { para preparações caseiras a fim } \\
\text { de atender as crianças da } \\
\text { creche. }\end{array}$ \\
\hline Fortaleza & $\begin{array}{l}\text { Movimento } \\
\text { de Saúde } \\
\text { Mental } \\
\text { Comunitária } \\
\text {-Bom Jardim }\end{array}$ & II & $S / \mathrm{I}^{\ddagger}$ & $\begin{array}{c}\text { Ativa. Produz Erva Cidreira } \\
\text { (Lippia alba) para preparação } \\
\text { de elixir o qual é dispensado no } \\
\text { CAPS SER VI, com prescrição } \\
\text { médica. }\end{array}$ \\
\hline Fortaleza & $\begin{array}{l}\text { Bairro São } \\
\text { Miguel }\end{array}$ & I & $S / \mathrm{I}^{\ddagger}$ & $\begin{array}{l}\text { Ativa. O Horto de Plantas } \\
\text { Medicinais foi instalado em } \\
\text { uma creche mantida pela } \\
\text { empresa Naturágua. }\end{array}$ \\
\hline Fortaleza & $\begin{array}{c}\text { Mulheres em } \\
\text { Movimento } \\
\text { da Itaoca }\end{array}$ & I & $\mathrm{S} / \mathrm{I}^{\ddagger}$ & $\begin{array}{c}\text { Ativa. Na fase de } \\
\text { processamento das plantas } \\
\text { medicinais apresenta um } \\
\text { espaço físico para secagem e } \\
\text { espaço para a produção de } \\
\text { mudas, com perspectiva de } \\
\text { adequar-se ao Modelo II. }\end{array}$ \\
\hline
\end{tabular}




\begin{tabular}{|c|c|c|c|c|}
\hline Fortaleza & $\begin{array}{l}\text { Associação O } \\
\text { Caminho }\end{array}$ & II & $\mathrm{S} / \mathrm{I}^{\ddagger}$ & $\begin{array}{l}\text { Em fase de implantação. } \\
\text { Funciona no }{ }^{* *} \text { CEU. Possibilita } \\
\text { aos ex-presidiários e } \\
\text { presidiários que estão em } \\
\text { regime aberto e semi-aberto } \\
\text { perspectivas de uma } \\
\text { reintegração social. }\end{array}$ \\
\hline Fortaleza & $\begin{array}{l}\text { Conjunto } \\
\text { Palmeiras }\end{array}$ & $\mathrm{N} / \mathrm{C}^{+}$ & $\mathrm{S} / \mathrm{I}^{\ddagger}$ & $\begin{array}{l}\text { Ativa. Caracteriza-se como um } \\
\text { movimento comunitário } \\
\text { também denominado } \\
\text { Laboratório de Agricultura } \\
\text { Urbana, onde os moradores } \\
\text { aprendem a fazer hortas e } \\
\text { pomares e a criar peixes e } \\
\text { galinhas caipiras (depois, o } \\
\text { projeto passa a ser } \\
\text { desenvolvido nos quintais das } \\
\text { casas; o que é produzido é } \\
\text { consumido pelas famílias e o } \\
\text { excedente é comercializado na } \\
\text { feira). }\end{array}$ \\
\hline Guaramiranga & $\begin{array}{l}\text { Sítio Nova } \\
\text { Olinda }\end{array}$ & I & 1994 & $\begin{array}{c}\text { Sem maiores informações } \\
\text { cadastrais. }\end{array}$ \\
\hline Iguatu & $\begin{array}{c}\text { Seminário } \\
\text { Diocesano de } \\
\text { Iguatu. }\end{array}$ & II & $\mathrm{S} / \mathrm{I}^{+}$ & $\begin{array}{l}\text { Em fase de implantação. } \\
\text { Funciona como importante } \\
\text { Centro de Encontros Educativos } \\
\text { para Seminaristas, Pastorais e } \\
\text { Comunidade da Região Centro } \\
\text { Sul do estado. }\end{array}$ \\
\hline Itaitinga & $\begin{array}{l}\text { Patativa do } \\
\text { Assaré }\end{array}$ & III & 1997 & $\begin{array}{l}\text { Inativa. Desativada devido } \\
\text { dificuldade de auto- } \\
\text { sustentabilidade. Chegou a } \\
\text { manter convênio com a } \\
\text { Prefeitura Municipal de } \\
\text { Itaitinga, mas sem sucesso. } \\
\text { Ainda possui canteiros. A } \\
\text { Oficina Farmacêutica foi } \\
\text { desativada. }\end{array}$ \\
\hline Maracanaú & $\begin{array}{l}\text { Fundação } \\
\text { Terra dos } \\
\text { Servos de } \\
\text { Deus }\end{array}$ & I & $\mathrm{S} / \mathrm{I}^{\ddagger}$ & $\begin{array}{c}\text { Em fase de implantação. A } \\
\text { Fundação oferece os serviços } \\
\text { da creche Pleno Viver às } \\
\text { crianças com idades de } 4 \text { meses } \\
\text { a } 3 \text { anos e } 11 \text { meses, moradoras } \\
\text { do bairro Alto Alegre II. }\end{array}$ \\
\hline
\end{tabular}




\begin{tabular}{|c|c|c|c|c|}
\hline Orós & $\begin{array}{c}\text { Projeto } \\
\text { Sertão Vivo }\end{array}$ & II & $S / I^{\ddagger}$ & $\begin{array}{l}\text { Em fase de implantação. } \\
\text { Localizado no Sítio Aroeiras, } \\
\text { distrito de Guassucê. O projeto } \\
\text { tem como objetivo oferecer } \\
\text { melhores condições de vida e } \\
\text { convívio no semiárido, para a } \\
\text { comunidade local. }\end{array}$ \\
\hline Redenção & $\begin{array}{l}\text { Hospital de } \\
\text { Dermatologia } \\
\text { Sanitária } \\
\text { Antonio } \\
\text { Diogo } \\
\text { (Leprosário } \\
\text { Antonio } \\
\text { Diogo) }\end{array}$ & $\mathrm{N} / \mathrm{C}^{+}$ & $S / I^{\ddagger}$ & $\begin{array}{l}\text { Inativa. É uma associação } \\
\text { privada. Possuía canteiros de } \\
\text { plantas medicinais. Recebia em } \\
\text { anos anteriores Pomada de } \\
\text { Confrei (Symphytum officinale) } \\
\text { da Secretaria de Saúde de } \\
\text { Fortaleza para curativos. }\end{array}$ \\
\hline $\begin{array}{l}\text { Santana do } \\
\text { Acaraú }\end{array}$ & $\begin{array}{c}\text { Pastoral da } \\
\text { Criança }\end{array}$ & I & $\mathrm{S} / \mathrm{I}^{\ddagger}$ & $\begin{array}{l}\text { Sem informações quanto a sua } \\
\text { atividade atual. A pastoral } \\
\text { reforça a importância da família } \\
\text { na saúde e educação das } \\
\text { crianças. }\end{array}$ \\
\hline Sobral & CEPEMA $^{++}$ & $\mathrm{N} / \mathrm{C}^{+}$ & 1994 & $\begin{array}{l}\text { Sem informações quanto a sua } \\
\text { atividade atual. A Fundação } \\
\text { trabalha com educação popular } \\
\text { na defesa do meio ambiente } \\
\text { em equilíbrio na relação entre } \\
\text { Ser Humano e Natureza. }\end{array}$ \\
\hline Tururú & $\begin{array}{l}\text { Movimento } \\
\text { Sem Terra }\end{array}$ & $\mathrm{N} / \mathrm{C}^{+}$ & $\mathrm{S} / \mathrm{I}^{\ddagger}$ & $\begin{array}{l}\text { Inativo. Esse movimento } \\
\text { recebeu verbas da FIOCRUZ } \\
\text { para implantação de } \\
\text { Laboratório Farmacêutico. O } \\
\text { NUFITO* deu apoio técnico- } \\
\text { científico para implantação de } \\
\text { um Horto de Plantas } \\
\text { Medicinais. O motivo para o } \\
\text { encerramento das atividades foi } \\
\text { a falta de água para irrigação e } \\
\text { verba para manutenção das } \\
\text { atividades. }\end{array}$ \\
\hline
\end{tabular}

Quadro 2. FV de natureza não governamental cadastradas pelo NUFITO, por município do estado do Ceará, com os respectivos modelos adotados e sua situação atual.

Fonte: Elaborado pelos autores (ANO). Núcleo de Fitoterápicos da Coordenadoria de Assistência Farmacêutica - *NUFITO (1983-2016). ${ }^{+} \mathrm{N} / \mathrm{C}$ - Não classificada. ${ }^{\ddagger} \mathrm{S} / \mathrm{I}$ - Sem informações. ${ }^{\circledR} \mathrm{SUS}$ - Sistema Único de Saúde. "IPREDE - Instituto de Prevenção a Desnutrição e a Excepcionalidade. "FAC - Fundação de Apoio Comunitário. ${ }^{* *}$ CEU Condomínio Espiritual Uirapuru. ${ }^{+}$CEPEMA - Fundação Cultural Educacional Popular em Defesa do Meio Ambiente. "FIOCRUZ - Fundação Oswaldo Cruz. 
Com relação aos modelos adotados, 13 (50\%) das Farmácias Vivas que funcionam em organizações não governamentais estão inseridas no modelo I, quatro $(15,4 \%)$ no modelo II, 04 (15,4\%) no modelo III e 05 (19,2\%) não possuíam essa informação em seus registros (Quadro 2).

As FV mantidas, exclusivamente, por instituições não governamentais se enquadram nos modelos I ou II, as que foram classificadas no modelo III possuem convênios com instituições governamentais. Isso acontece por que, para ser modelo III, a Farmácia Viva obrigatoriamente deve estar conveniada ao SUS, uma vez que, os fitoterápicos devem ser destinados ao provimento de unidades desse sistema e segundo a portaria n 886 de 2010, que institui a Farmácia Viva no âmbito do SUS, em seu segundo parágrafo, é proibida a comercialização de plantas medicinais e fitoterápicos elaborados a partir das FV ${ }^{7}$.

Não foi encontrada na literatura consultada, qualquer outra referência a graus de complexidade em fitoterapia, ou seja, aos modelos de Farmácia Viva I, II e III o que denota, mais uma vez, o pioneirismo do estado do Ceará na área.

Não foram encontradas informações sobre o ano de implantação de 19 (73\%) das Farmácias Vivas de natureza não governamentais. As 26 unidades de FV de natureza não governamental foram instaladas em 14 municípios diferentes, sendo 11 delas, só no município de Fortaleza. Atualmente, nove (34,6\%) Farmácias Vivas implantadas em instituições privadas estão em atividade, 07 (26,9\%) estão inativas, 04 (15,4\%) estão em fase de implantação e seis $(23,1 \%)$ não apresentavam essa informação em seus registros.

Nas Farmácias Vivas de natureza não governamental, quatro $(15,3 \%)$ apresentaram como principal motivo para a descontinuidades das ações a falta de verbas para a manutenção e em uma (3,8\%), o fim das atividades se deu por espaço inadequado para o cultivo, contaminação do solo e acesso à água insuficiente.

Dessa forma, nota-se que a maioria das dificuldades enfrentadas para o adequado funcionamento da unidade de FV, de natureza governamental ou não governamental, está relacionada direta ou indiretamente a escassez de recursos financeiros. Essa realidade pode 
ser atribuída a descontinuidade de políticas públicas na área de plantas medicinais e fitoterapia sem a garantia de verbas permanentes para o desempenho das ações. ${ }^{1}$

Além dessas FV, foram encontrados tanto no Horto Matriz quanto no Horto Oficial registros de FV implantadas em universidades e faculdades públicas e privadas do estado do Ceará. O Quadro 3 apresenta os locais, por município, modelo e situação atual.

\begin{tabular}{|c|c|c|c|c|}
\hline Município & Nome & Modelo & $\begin{array}{c}\text { Ano de } \\
\text { implantação }\end{array}$ & Situação atual \\
\hline Crato & UVA $^{*}$ & I & $\mathrm{S} / \mathrm{I}^{+}$ & $\begin{array}{l}\text { Ativa. Em fase de reestruturação. Possui Horto de } \\
\text { Plantas Medicinais em apoio ao ensino, pesquisa } \\
\text { e extensão. }\end{array}$ \\
\hline Fortaleza & $\begin{array}{l}\text { Programa } \\
\text { Farmácia Viva } \\
\text { e Horto de } \\
\text { Plantas } \\
\text { medicinais } \\
\text { Francisco José } \\
\text { de Abreu } \\
\text { Matos }\end{array}$ & $\begin{array}{l}\text { Horto } \\
\text { Matriz I }\end{array}$ & 1983 & $\begin{array}{l}\text { Ativa. O Horto Matriz (Decreto no 30.016/2009) } \\
\text { situado na Universidade Federal do Ceará } \\
\text { constitui em campo de prática, presta apoio } \\
\text { técnico científico à outras FV e realiza } \\
\text { orientações sobre o uso seguro de plantas } \\
\text { medicinais e fitoterápicos à comunidade. }\end{array}$ \\
\hline Fortaleza & $\mathrm{NEPAU}^{\ddagger} / \mathrm{UFC}^{\S}$ & II & $\mathrm{S} / \mathrm{I}^{+}$ & $\begin{array}{l}\text { Ativa. Oferece apoio às atividades de agricultura } \\
\text { urbana e capacita o público interessado neste } \\
\text { campo de conhecimento, proporciona } \\
\text { oportunidades de aprendizagem segundo a } \\
\text { metodologia do aprender-fazendo para alunos } \\
\text { de graduação de agronomia. As ações de } \\
\text { extensão realizadas no NEPAU,, mediante a } \\
\text { realização de cursos teórico-práticos, } \\
\text { oportunizam a implementação de programas de } \\
\text { agricultura urbana com o cultivo de hortaliças, } \\
\text { plantas medicinais, ornamentais, produção de } \\
\text { mudas para arborização urbana, entre outros. }\end{array}$ \\
\hline Fortaleza & $\begin{array}{l}\text { CEDEFAM"l / } \\
\text { Pró-Reitora de } \\
\text { Extensão - } \\
\text { UFC }\end{array}$ & I & 1994 & $\begin{array}{l}\text { Inativa. Não possuía condições técnicas de } \\
\text { continuar com as características de Modelo III, } \\
\text { segundo Decreto no } 30.016 / 2009 \text {, então, } \\
\text { permutou para modelo I. Existia integração com } \\
\text { a Secretaria de Saúde de Fortaleza. A preparação } \\
\text { de fitoterápicos foi direcionada para uma única } \\
\text { oficina farmacêutica (Lúcia Gurgel) para a } \\
\text { garantia da qualidade. }\end{array}$ \\
\hline Fortaleza & UNIFOR ${ }^{\pi}$ & III & $\mathrm{S} / \mathrm{I}^{+}$ & $\begin{array}{l}\text { Ativa. Desenvolve trabalhos integrados à } \\
\text { Secretaria de Saúde de Fortaleza. }\end{array}$ \\
\hline
\end{tabular}




\begin{tabular}{|c|c|c|c|c|}
\hline Fortaleza & UNICHRISTUS ${ }^{* *}$ & I & $S / I^{+}$ & $\begin{array}{l}\text { Em processo de implantação no Campus Parque } \\
\text { Ecológico da UNICHRISTUS }{ }^{* *} \text { - Cocó como } \\
\text { atividade de ensino, pesquisa e extensão. }\end{array}$ \\
\hline Fortaleza & FAMETRO $^{++}$ & I & $\mathrm{S} / \mathrm{I}^{+}$ & $\begin{array}{l}\text { Ativa. Com perspectiva para permutar para } \\
\text { Modelo III em integração com a Farmácia Escola } \\
\text { da Instituição, com a finalidade de preparar } \\
\text { fitoterápicos e promover ensino e extensão. }\end{array}$ \\
\hline Fortaleza & FATECE $^{\neq \neq}$ & I & $\mathrm{S} / \mathrm{I}^{+}$ & atividades de ensino e extensão. \\
\hline Iguatu & $\begin{array}{l}\text { UECE§§/ } \\
\text { Faculdade de } \\
\text { Educação, } \\
\text { Ciências e } \\
\text { Letras de } \\
\text { Iguatu }\end{array}$ & I & $\mathrm{S} / \mathrm{I}^{+}$ & $\begin{array}{l}\text { Inativa. Desenvolveram atividades em anos } \\
\text { anteriores. Possui canteiros, mas desativados. }\end{array}$ \\
\hline $\begin{array}{l}\text { Juazeiro do } \\
\text { Norte }\end{array}$ & $\begin{array}{l}\text { Faculdade de } \\
\text { Medicina } \\
\text { Estácio de } \\
\text { Juazeiro do } \\
\text { Norte }\end{array}$ & I & $\mathrm{S} / \mathrm{I}^{+}$ & $\begin{array}{l}\text { Em fase de reestruturação. Possui Horto de } \\
\text { Plantas Medicinais em apoio ao ensino, pesquisa } \\
\text { e extensão. }\end{array}$ \\
\hline Pacoti & $\begin{array}{l}\text { Campus } \\
\text { Experimental } \\
\text { de Educação } \\
\text { Ambiental e } \\
\text { Ecologia / } \\
\text { UECE }^{\S \S}\end{array}$ & $\mathrm{N} / \mathrm{C}^{||||}$ & $\mathrm{S} / \mathrm{I}^{+}$ & $\begin{array}{l}\text { Em fase de reestruturação. Destina-se a estudos } \\
\text { voltados para a defesa e preservação ambiental e } \\
\text { em apoio educativo às Escolas Públicas do } \\
\text { Município. }\end{array}$ \\
\hline Pentecoste & $\begin{array}{l}\text { Fazenda } \\
\text { Experimental } \\
\text { do Vale do } \\
\text { Curu / UFC }\end{array}$ & I & 1998 & $\begin{array}{l}\text { Ativa. Há alguns anos funcionou como Modelo III } \\
\text { integrada à Secretaria de Saúde de Pentecoste. } \\
\text { Ligada ao Curso de Agronomia, destina-se a } \\
\text { servir como unidade de apoio nas atividades de } \\
\text { pesquisa, ensino, extensão e produção. Com } \\
\text { potencial para modelo II. }\end{array}$ \\
\hline Quixadá & $\begin{array}{l}\text { Faculdade } \\
\text { Católica Rainha } \\
\text { do Sertão / } \\
\text { UNICATÓLICA }\end{array}$ & III & $\mathrm{S} / \mathrm{I}^{+}$ & $\begin{array}{l}\text { Ativa. Possui Horto de Plantas Medicinais e } \\
\text { Oficina Farmacêutica com pequena produção de } \\
\text { fitoterápicos, em apoio ao ensino e extensão. }\end{array}$ \\
\hline Sobral & UVA $^{*}$ & I & 1993 & $\begin{array}{l}\text { Ativa. Possui Horto de Plantas Medicinais em } \\
\text { apoio ao ensino e extensão. }\end{array}$ \\
\hline Sobral & INTA $^{* * * *}$ & III & $\mathrm{S} / \mathrm{I}^{+}$ & $\begin{array}{c}\text { Ativa. Desenvolve trabalhos integrados à } \\
\text { Secretaria de Saúde de Sobral. Em fase de } \\
\text { estruturação do seu próprio Horto de Plantas } \\
\text { Medicinais. }\end{array}$ \\
\hline
\end{tabular}

Quadro 3. FV implantas em Faculdades e Universidades cadastradas pelo NUFITO, por município do estado do Ceará, com os respectivos modelos adotados e sua situação atual.

Fonte: Elaborado pelos autores (ANO). Núcleo de Fitoterápicos da Coordenadoria de Assistência Farmacêutica 


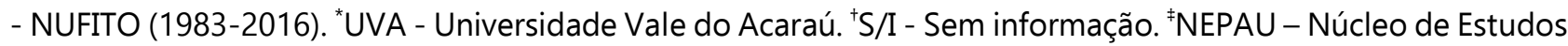
e Pesquisas de Agricultura Urbana. ${ }^{S}$ UFC - Universidade Federal do Ceará. "CEDEFAM - Centro de Desenvolvimento Familiar. "UNIFOR - Universidade de Fortaleza. ${ }^{*}$ UNICHRISTUS - Centro Universitário

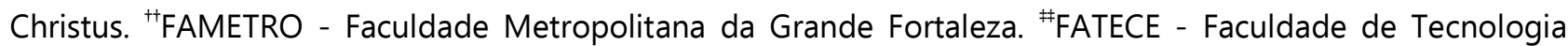
Intensiva. ${ }^{\S}$ UECE - Universidade Estadual do Ceará. IIIIN/C - Não classificada. " UNIICATÓLICA - Centro Universitário Católica de Quixadá. ${ }^{* * *}$ INTA - Instituto Superior de Teologia Aplicada.

Com relação aos seus modelos, 10 (66,6\%) unidades de Farmácias Vivas implantadas em universidades ou faculdades se enquadravam no modelo I, uma $(6,7 \%)$ no modelo II, três (20\%) no modelo III e uma $(6,7 \%)$ não foi classificada. Não havia o registro do ano de implantação de 11 (73,3\%) FV inseridas em instituições de ensino superior. As 15 unidades de FV foram distribuídas em oito municípios diferentes, sendo sete unidades só no município de Fortaleza. Atualmente, nove (60\%) FV estão em atividade, duas (13,3\%) em fase de implantação, duas (13,3\%) em fase de reestruturação e duas (13,3\%) encontram-se inativas (Quadro 3).

Há dez anos as práticas integrativas e complementares já são reconhecidas enquanto política de saúde pelo SUS, entretanto, ainda são poucas as instituições de ensino superior que oferecem disciplinas relacionadas ao tema. As poucas instituições que se propõem a oferecer, o fazem de maneira optativa. Levando-se em consideração que os acadêmicos da área de saúde não são estimulados a buscarem essas disciplinas em meio a hegemonia do modelo biomédico, grande parte dos profissionais de saúde no Brasil, está se formando sem nenhuma aproximação acadêmica do saber popular. Somente com o conhecimento da cultura tradicional o profissional estará apto a discutir as vantagens e as desvantagens do uso dessas práticas com os pacientes que desejem utilizá-las ou para os que já fazem uso, algumas vezes de forma inadequada, como é o caso do uso de fitoterápicos. ${ }^{13}$

O Gráfico 1 apresenta os graus de complexidade das FV situadas em instituiç̧̃̃es governamentais, não governamentais e em instituições de ensino superior, nos três casos o modelo I, o menos complexo prevalece. Esse resultado demonstra que, a população cearense está tendo um acesso restrito a medicamentos fitoterápicos com eficácia 
comprovada, com procedência segura e produzido pelas boas práticas de cultivo e preparação dos produtos finais, como os que são produzidos nas Farmácias Vivas.

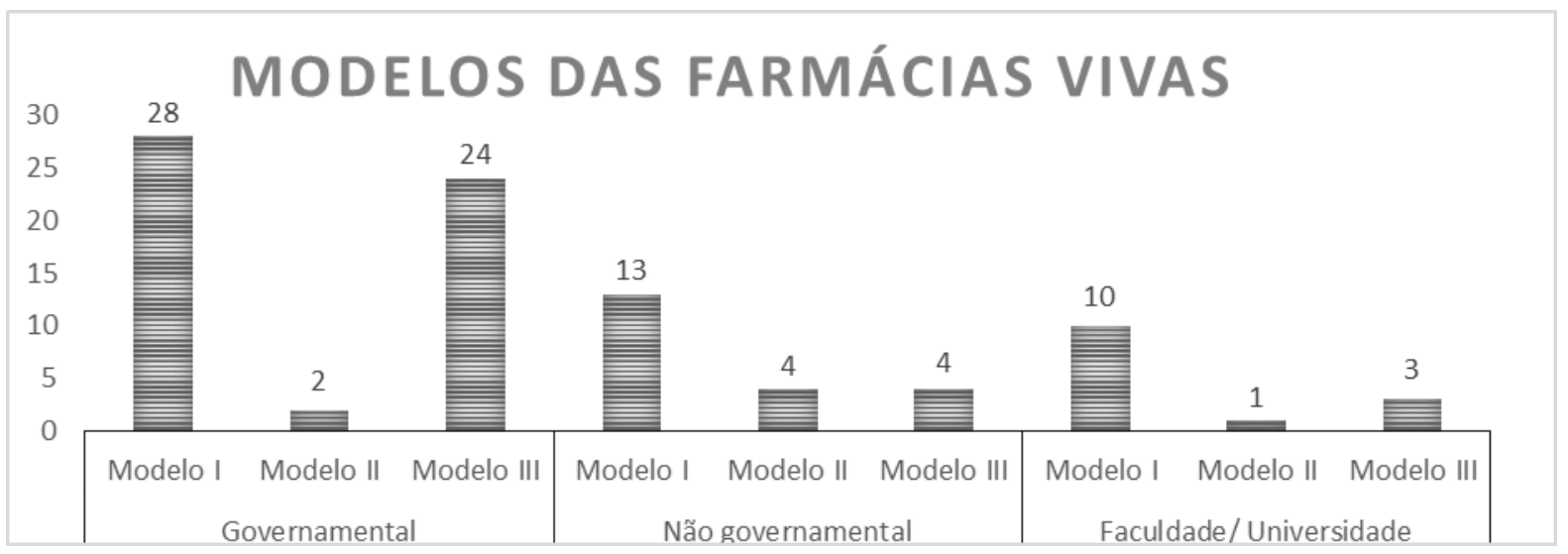

Gráfico 1. Modelo (graus de complexidade) das Farmácias Vivas de natureza governamental, não governamental e implantadas em instituições de ensino superior.

Fonte: Elaborado pelos autores (2016).

Desde a criação do programa Farmácias Vivas, em 1983, foram implantas 99 unidades em instituições de natureza governamental, não governamental e em instituições de ensino superior. O programa conta com, atualmente, com 42 unidades em atividade.

A partir do Gráfico 2 é possível perceber as Farmácias Vivas implantadas em instituições governamentais sofreram o maior número de descontinuidade, 26 unidades foram inativadas tendo, mais unidades inativas do que as 24 unidades que estão em atividade atualmente. As instituições governamentais e as instituições de ensino superior apresentam mais unidades de FV ativas do que inativas.

O Decreto regulamentador $n^{\circ} 30.016$ (2009) recomendou ainda, a implantação ou implementação de unidades de Farmácias Vivas (governamentais) nas Microrregionais de Saúde, de forma a garantir o acesso às plantas medicinais e fitoterápicos, com segurança, eficácia e qualidade, a todas as regiões do estado do Ceará. ${ }^{6}$ 


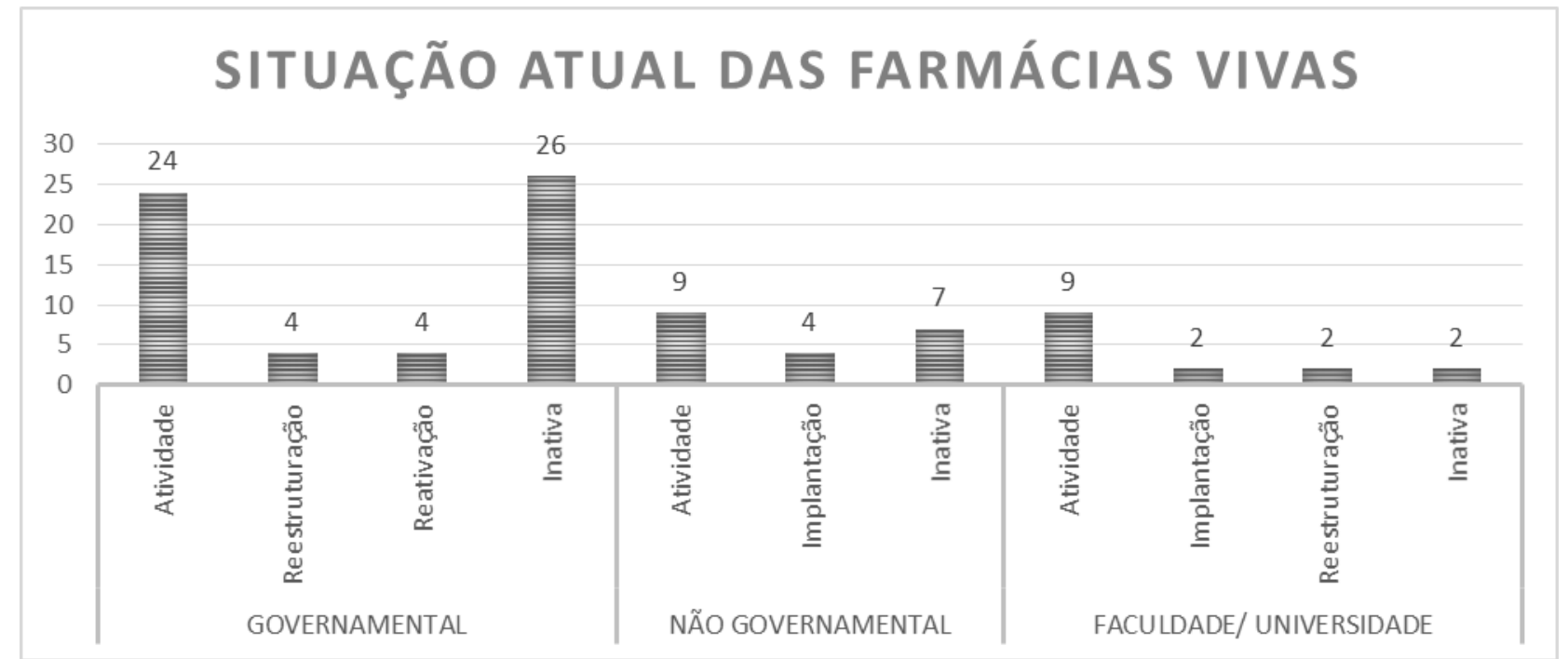

Gráfico 2. Situação atual das Farmácias Vivas (atividade, reestruturação, reativação, inativa ou implantação) de natureza governamental, não governamental e implantadas em instituições de ensino superior. Fonte: Elaborado pelos autores (2016).

A macrorregião de saúde de Fortaleza conta com 17 unidades no total, sendo a macrorregião com a maior concentração de Farmácias Vivas, a macrorregião de saúde de Sobral possui 06 unidades e a do Litoral Leste/Jaguaribe 03 unidades de Farmácia Viva. Foram encontrados registros de 01 unidade de FV nas macrorregiões de saúde do Sertão Central e a do Cariri, cada uma.

Com relação às microrregiões de saúde, foram encontrados registros de Farmácias Vivas em 15 microrregiões de saúde, das 22 existentes. A $1^{\text {a }}$ Cordenadoria Regional de Saúde - CRES - Fortaleza apresenta o maior número de unidade 09 (30\%) no total, em seguida encontra-se a $3^{a}$ CRES - Maracanaú e a $11^{\text {a }}$ CRES Sobral com 04 (13,3\%), cada uma. A 10 CRES - Limoeiro do Norte conta com 03 Farmácias Vivas, a $6^{a}$ CRES - Itapipoca e a $13^{a}$ CRES - Tianguá apresentam, cada uma, 02 unidades. As demais microrregiões, $2^{a}$ CRES - Caucaia, $4^{\text {a }}$ CRES - Baturité, 8ª CRES - Quixadá, 19a CRES - Brejo Santo e $22^{a}$ CRES - Cascavel (que não pertence a nenhuma macrorregião de saúde) contam com 01 unidade da Farmácia Viva, cada. 
A maior concentração de Farmácias Vivas na Capital do estado do Ceará e regiões metropolitanas pode ser explicada justamente pela proximidade dessas regiões com o Horto Matriz/UFC e o Horto Oficial/ NUFITO o que favorece a obtenção das mudas com certificação botânica, bem como, a orientação técnico-científica dessas instituições. Diante dessa realidade, fica evidente a necessidade de descentralizar as Farmácias Vivas em todas as regiões do estado conforme preconizou o Decreto $n^{\circ} 30.016 / 2009$, a fim de garantir que toda a população cearense tenha acesso a essa forma de tratamento, especialmente, a de baixa renda.

Os Arranjos Produtivos Locais - APL de plantas medicinais e fitoterápicos podem ser uma alternativa à sustentabilidade das Farmácias Vivas por serem uma opção para ampliar a produção de plantas medicinais por meio da cooperação entre pequenos agricultores com vistas à produção de fitoterápicos para dispensação nas unidades de saúde do SUS.

O Edital nº1/2013 é um exemplo de iniciativa de financiamento para projeto na área de Plantas Medicinais e Fitoterápicos, o qual aborda a seleção pública de projetos de arranjo produtivo local de plantas medicinais e fitoterápicos no campo do SUS. ${ }^{14}$

Documentos do NUFITO apontam que o Ceará, por meio da sua Secretaria de Saúde e com apoio da Universidade Federal do Ceará, foi selecionado para desenvolver o Projeto "Horto de Plantas Medicinais Polos em Macrorregiões no Estado do Ceará: Estruturação e Fortalecimento dos Arranjos Produtivos Locais para Produção de Plantas Medicinais e Fitoterápicos para o SUS". ${ }^{15}$

O referido projeto propõe o estabelecimento de parcerias, interação e cooperação entre os agentes da cadeia de plantas medicinais e fitoterápicos; o desenvolvimento da produção de fitoterápicos e/ou insumos de origem vegetal e/ou plantas medicinais, considerando a agricultura familiar urbana e periurbana, descentralizando o acesso à plantas medicinais e/ou fitoterápicos, o conhecimento tradicional e o científico como componentes da cadeia produtiva; a sensibilização e qualificação técnica dos profissionais de saúde e demais envolvidos na produção e uso de plantas medicinais e fitoterápicos; a implantação 
e/ou implementação de ações que garantam a dispensação de plantas medicinais e fitoterápicos no âmbito do SUS e a articulação entre políticas públicas intersetoriais e transversais ao Programa Nacional de Plantas Medicinais e Fitoterápicos. ${ }^{15}$

No Ceará, as experiências desenvolvidas com as Farmácias Vivas modelo III demonstram que um dos fatores limitantes na produção de fitoterápicos é a produção de matéria-prima, pois esta fica sob a responsabilidade do Horto de Plantas Medicinais do município, onde se desenvolvem os serviços de fitoterapia. Dessa forma, o referido edital ( $n^{\circ}$ 01/2013) do Ministério da Saúde vem ao encontro dessa necessidade como forma de ampliar essas ações. $^{14}$

Para tanto, a secretaria de saúde do estado do Ceará propôs a implantação e/ou implementação de Hortos de Plantas Medicinais - Polo para apoio técnico e integração com os Arranjos Produtivos Locais de plantas medicinais e fitoterápicos (designados Hortos APLs), os quais fornecerão matéria-prima para a prefeitura local, que agregará valor financeiro, bem como a Indústria Farmacêutica, a se interessar. ${ }^{15}$

\section{Considerações finais}

Os dados obtidos a partir desse trabalho revelam que a maioria das Farmácias Vivas está inserida no modelo I, ou seja, o menos complexo. Segundo as informações do Horto Matriz e do Horto Oficial, 39 Farmácias Vivas sofreram descontinuidade ao longo dos 34 anos do programa. As Farmácias Vivas de natureza governamental apresentaram o maior número de unidades inativas o que pode estar relacionado à incapacidade dos órgãos públicos em se adequar às exigências do Decreto regulamentador n³ 30.016/2009.

O estudo apresentou como principal limitação a impossibilidade de ver a situação de cada Farmácia Viva in loco.

Percebe-se que o principal desafio que se impõe ao Programa Farmácias Vivas é a falta de financiamento específico e permanente que garanta a expansão do programa e manutenção das unidades já implantadas nos municípios do estado do Ceará. 


\section{Referências}

1. Ceará. Comitê Estadual de Fitoterapia. A fitoterapia no ciclo da assistência farmacêutica: inserção das Farmácias Vivas. Fortaleza: HBM Shopping das cópias; 2015. 72 p.

2. Rufino LL. Farmácias Vivas: o contexto do uso de plantas medicinais e fitoterápicos por meio dos atores sociais no município de Fortaleza [dissertação]. Fortaleza: Universidade Federal do Ceará; 2015.

3. Marques KM. Francisco José de Abreu Matos: vida escolar, ensino, pesquisa e extensão em fatos (1924-2008) [dissertação]. Fortaleza: Universidade Federal do Ceará; 2016.

4. Matos FJA. Farmácias Vivas: sistema de utilização de plantas medicinais projetado para pequenas comunidades. 2a rev. ampl. Ed. Fortaleza: Edições UFC. 2002. 267 p.

5. Secretaria da Saúde do Estado do Ceará. Lei Estadual n 12.951, de 07 de outubro de 1999. Dispõe sobre a Política de Implantação da Fitoterapia em Saúde Pública no Estado do Ceará. Diário Oficial do Estado do Ceará, Fortaleza (1999 out. 8); Caderno 1:8.

6. Secretaria da Saúde do Estado do Ceará. Decreto $n^{\circ}$ 30.016, de 30 de dezembro de 2009. Regulamenta a Lei $N^{0} 12.951$, de 07 de outubro de 1999, que dispõe sobre a política de implantação da fitoterapia em saúde pública no estado do Ceará e dá outras providências. Diário Oficial do Estado do Ceará, Fortaleza (2010 jan. 8); Caderno 1:8.

7. Ministério de Saúde. Portaria $n^{\circ} 886$, de 20 de abril de 2010. Institui a Farmácia Viva no âmbito do Sistema Único de Saúde (SUS). Diário Oficial da União, Brasília, DF (2010 abr. 22); Sec 1:75.

8. Ministério da Saúde. Secretaria de Atenção à Saúde. Portaria $n^{\circ} 470$, de 19 de agosto de 2011. Inclui na Tabela de Serviços/Classificação do Sistema de Cadastro Nacional de Estabelecimentos de Saúde - SCNES no serviço de código 125 - Serviço de Farmácia, a classificação 007 Farmácia Viva. Diário Oficial da União, Brasília, DF (2011 ago. 23); Sec $1: 22$.

9. Brasil. Ministério da Saúde. Secretaria de Atenção à Saúde. Departamento da Atenção Básica. Política Nacional de Práticas Integrativas e Complementares no SUS - PNPIC. Brasília, DF: Ministério da Saúde; 2006.

10. Brasil. Ministério da Saúde. Secretaria de Ciência, Tecnologia e Insumos Estratégicos. 
Departamento de Assistência Farmacêutica. Política nacional de plantas medicinais e fitoterápicos. Brasília, DF: Ministério da Saúde; 2006.

11. Brasil. Ministério da Saúde. Secretaria de Ciência, Tecnologia e Insumos Estratégicos. Departamento de Assistência Farmacêutica e Insumos Estratégicos. Programa Nacional de Plantas Medicinais e Fitoterápicos. Brasília, DF: Ministério da Saúde; 2009.

12. Agência Nacional de Vigilância Sanitária. Resolução - RDC n 18, de 3 de abril de 2013. Dispõe sobre as boas práticas de processamento e armazenamento de plantas medicinais, preparação e dispensação de produtos magistrais e oficinais de plantas medicinais e fitoterápicos em farmácias vivas no âmbito do Sistema Único de Saúde (SUS). Diário Oficial da União, Brasília, DF (2013 abr.). Disponível em http://bvsms.saude.gov.br/bvs/saudelegis/anvisa/2013/rdc0018_03_04_2013.html.

13. Salles LF, Homo RFB, Silva MJP. Situação do ensino das práticas integrativas e complementares nos cursos de graduação em enfermagem, fisioterapia e medicina. Cogitare Enferm. 2014;19(4):741-6. http://dx.doi.org/10.5380/ce.v19i4.35140

14. Brasil. Ministério da Saúde. Secretaria de Ciência, Tecnologia e Insumos Estratégicos. Seleção pública de projetos de arranjo produtivo local de plantas medicinais e fitoterápicos no âmbito do SUS. Edital nº 01, de 24 de maio de 2013. Brasília, DF: Ministério da Saúde; 2013.

15. Ceará. Secretaria da Saúde do Estado do Ceará. Coordenadoria de Assistência Farmacêutica da Secretaria de Saúde do Estado do Ceará - COASF. Núcleo de Fitoterápicos - NUFITO. Horto de Plantas Medicinais Polos em Macrorregiões no Estado do Ceará: Estruturação e Fortalecimento dos Arranjos Produtivos Locais para Produção de Plantas Medicinais e Fitoterápicos para o SUS. Fortaleza: Secretaria da Saúde do Estado do Ceará; 2013.

16. Brasil. Agência Nacional de Vigilância Sanitária. Formulário Nacional da Farmacopéia Brasileira. Brasília, DF: Ministério da Saúde; 2012. 


\section{Minicurrículo}

Danuta Yelena Goiana Bonfim | ORCiD: 0000-0002-9807-5929

Mestre em saúde da Família. Enfermeira assistencial do Hospital Universitário de Brasília, Brasília, DF, Brasil.

Aleksandra Barroso Gomes | ORCiD: 0000-0001-7247-5636

Especialista em Assistência Farmacêutica. Gerente da garantia da qualidade da Secretaria da Saúde do Estado do Ceará, Fortaleza, $\mathrm{CE}$, Brasil.

Angélica Regina Lima Brasil | ORCiD: 0000-0001-8267-3986

Especialista em Assistência Farmacêutica, Fortaleza, CE, Brasil.

Karla do Nascimento Magalhães | ORCiD: 0000-0003-1248-5669

Mestre em Farmacologia. Farmacêutica na Prefeitura Municipal de Fortaleza e na Universidade Federal do Ceará - UFC, Departamento de Farmácia, Laboratório de Farmacognosia. Fortaleza, CE, Brasil.

Kellen Miranda Sá | ORCiD: 0000-0001-7490-086X

Mestre em Políticas Públicas e Gestão do Ensino Superior. Farmacêutica no Laboratório de produtos Naturaisd doHorto de Plantas Medicinais Prof. Francisco José de Abreu Matos - Pró-reitoria de Pesquisa e Pós-graduação da Universidade Federal do Ceará - UFC, Fortaleza, CE, Brasil.

Mary Anne Medeiros Bandeira | ORCiD: 0000-0003-4301-4739

Doutora em Química. Diretora do Horto de Plantas Medicinais Francisco José de Abreu Matos, Coordenadora do Programa Farmácias Vivas/UFC, Supervisora do Núcleo de Fitoterápicos da Coordenadoria de Assistência Farmacêutica da Secretaria de Saúde do Estado do Ceará, Coordenadora do Comitê Estadual de Fitoterapia do estado do Ceará e Membro do Comitê Nacional de Plantas Medicinais e Fitoterápicos, Fortaleza, CE, Brasil. 